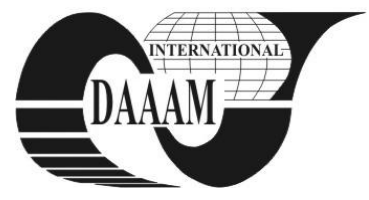

Annals of DAAAM for 2011 \& Proceedings of the 22nd International DAAAM Symposium, Volume 22, No. 1, ISSN 1726-9679 ISBN 978-3-901509-83-4, Editor B. Katalinic, Published by DAAAM International, Vienna, Austria, EU, 2011 Make Harmony between Technology and Nature, and Your Mind will Fly Free as a Bird Annals \& Proceedings of DAAAM International 2011

\title{
A MINDREADER SYSTEM FOR IMPROVED SECURITY IN CROWDED AREAS
}

\author{
SEVCIK, D[avid]; ADAMEK, M[ilan] \& JURIKOVA, L[ucie]
}

\begin{abstract}
The objective of this paper is to point out the development of the modern method of the mindreader security system. It deals with its utilization, function and identifying factors of a suspected person. Further, it outlines the individual types of these devices available in the market at present or the ones that will be launched into the market in the future. It also deals with the advantages of the facility compared to the existing methods of detection. The system introduces into the field of security new methods of scanning the physiological expressions of the human body, which enables an increase of security in crowded areas.
\end{abstract}

Key words: mindreader system, suspected person, mobile unit, security, physiological expressions

\section{INTRODUCTION}

Locations associated with risks with high probabilities of exposure to hazards, where there are large numbers of people present, are airports, border checkpoints, football stadiums, means of public transport and others.

It is difficult to monitor suspected people at these places. Moreover, the controlling process is time consuming and bothering. Although the modern detection devices are intended for detecting dangerous materials such as explosives, weapons or their parts, the disadvantage is in the conscious control of an individual. The mindreader is a part of a mobile unit; it is customised in such a way as to prevent a person from knowing he or she is being scanned. Thus, it ensures that the individual emits the microscopic physical signals which he or she ignores and is not capable of controlling. The very same signals are being recognised by the mindreader systems, for instance during the person's passing through the scanner.

\section{COMMONLY USED METHODS OF READING THOUGHTS}

Nowadays people can meet with some methods of reading thoughts, but these methods are mainly used in healty services, for example method of functional magnetic resonance imaging (fMRI).

\subsection{Contact Systems of reading thoughts}

It is used at people, who can't communicate individually. We use a net electrode, which is connected on a head, exactly into areas of speech brain centres, by conductive gel.

It is neccessary for computer to make up a database of the most often required words (yes, no, heat, chill, a little, a lot, hunger, thirst etc.) in first phase. It is done by healthy person, who thinks of these words at first and then tell them aloud.

It was found, that a brain transmits the same signals in case we tell or think about this word. A computer saves these informations into its own database. After a pacient attaching to this system, the computer evaluates changes in areas of speech brain centres and than compares them with its own database.
Afterwards it looks for the best sameness. A success of these method is about $80 \%$ (Korenar, 2011).

\subsection{Reading thoughts by tomograf}

A tomograf (or fMRI) is used for reading thoughts. This method can display right that's part of brain, which does some aktivity. Firstly, It is neccessary to learn the computer how a brain's aktivity is connected with specific external percept. It 's done i.e. by set of pictures, which are examined by observe person. The computer saves how a brain reacted on a particular picture. Afterwards, when the observed person looks at she similar pictures, the computer compares a present brain's activity with the activity saved in its own system and tries to find the best sameness (Singer, 2009).

\subsection{Reading thoughts by video cameras, sensor and lasers}

This method is non - invasive and non - contact, which can be used to improve security in airports, border crossing, football stadions etc.

Big advantage is, that potencional offender doesn't know he is monitored, that's why he doesn't have to try to change his behaviour any way. It's sure he would do it in case we would use i.e. tomograf or polygraf. Main principle is monitoring and than evaluation of micro - expressions changes on face of an investigated person.

\section{EMOTIONS}

In 1960 Dr. Paul Ekman discovered that even when people try to conceal what they are about to do they are being betrayed by a frail face-play known as "micro expressions". For instance, if a person shows his or her teeth for a split second, he or she lowers the eyebrows and nose wrinkles while pretending he or she is smiling, he or she has just used a micro expression of disgust.

The system can recognise seven basic emotions and emotional clues so far. These are anger, disgust, fear, joy, sadness and surprise. Eventually, the device will be capable of the analysis of the gait; an eye tracker and a pheromones scanner will follow. More importantly, it is necessary to mention that the system is pre-set by its advance designers in such a way to differentiate between a potential terrorist and a merely stressed person.

The system also counts on "the provocation" of eventual terrorists. For instance, a symbol or a picture connected to the terrorist group and known only by a terrorist will be positioned in the airport. The point is that people cannot fully control their reactions and thus if a person notices a familiar image at an unknown place he or she responds to it even if imperceptibly. And the very reactions are being perceived by the system. It could for example be eyes ticking, accelerated heartbeat, neurotic twitch or rapid breathing.

Therefore, it is possible to segregate the suspected person from a great number of people and perform an individual interview with them (Marks, 2007). 


\section{DEVELOPMENT TRENDS}

Since 2003, the USA's Transportation Security Administration (TSA) have been using a programme called Screening Passengers through Observation Techniques (SPOT) based on micro expressions. Within the scope of the SPOT programme the officials are being trained to observe and decode micro expressions of people to be found at airports. The programme enables them to draw aside a person whose micro expressions seem suspicious. Based on their answers during a routine interview the people are committed to further questioning. "We have caught a number of individuals, from drug dealers to money launderers, and a double murderer in one case," told the spokesman of the TSA Chris White.

However, the biggest issue remains in SPOT being a very expensive and demanding process. It cannot be included in the common scope of employment of a customs officer. "Right now, screeners have typically less than one minute to examine a traveller's documents and assess whether they are a threat," says the spokesman of the DHS Larry Orluskie (Barrie, 2008).

After SPOT, the Project Hostile Intent (PHI) emerged. Its aim is to identify facial expressions. The DHS hopes that after the automation of SPOT there will be computers not people that explore the micro expressions and at the same time they will disclose other physical symptoms that can be examined. Not only will the machines observe the facial micro expressions but they will also monitor gait, blood pressure, pulse and perspiration that are typical of hostility or the desire to deceive. For these purposes a remotely controlled, non-contact version of the polygraph, bouncing lasers or microwaves off a person's skin can be used, which was suggested by the American Department of Homeland Security in 2006. The DHS is about to employ the remote sensors in such a way that they do not restrict the flow of passengers. The project Advanced Research Projects Agency (HSARPA) of the U.S. Department of Homeland Security indicates that these sensors may include heart rate and breathing sensors, infrared light, laser, video, audio and eye tracking.

In September 2008 the Department of Homeland Security introduced a project called Future Attribute Screening Technology (FAST) and a joint project Homeland Security Advanced Research Agency and Science \& Technology Human Factors Behavior/Science Division of DHS.

The system of the biometric parts of the experiment is called MALINTENT; it is designated for revealing people with indications of malevolent intentions.

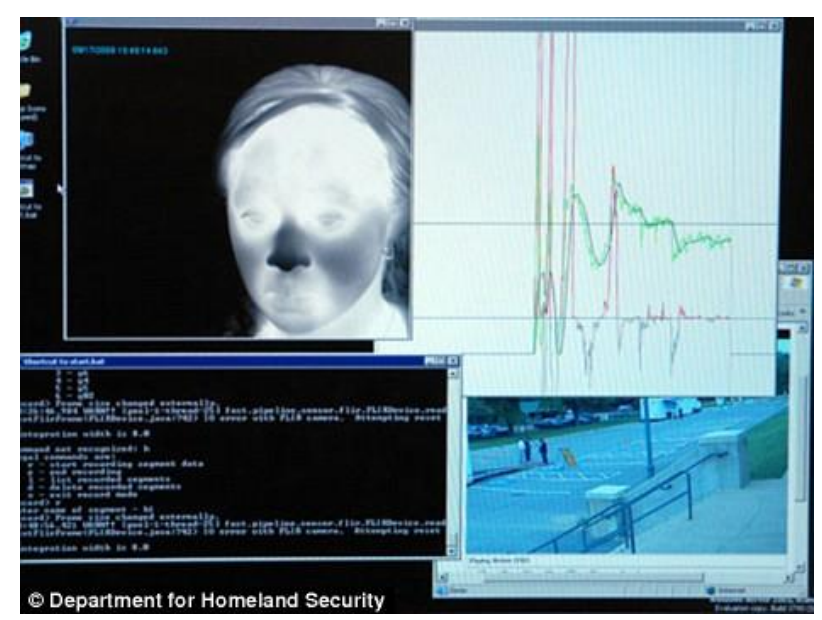

Fig. 1. The record of the mindreader system (Hazelton, 2008)

MALINTENT has been developed by the U.S. Department of Homeland Security within the Human Factors division. It is located in a mobile laboratory unit made by the Battelle company in Aberdeen, Maryland. It is a mobile checkpoint that can be transported where needed, for instance to airports, shipping ports, stations, border checkpoints and even in front of a football stadium. Anywhere where one can expect a large flow of people. A controlled person passes through this unit without knowing he or she is being scanned. The data provided by the sensors and cameras is being processed and by means of the algorithms it is determined whether the examined person is a danger or not. In case the person is evaluated as being dangerous the system notifies the operator who invites the person for a detailed interview. Furthermore, it is up to experienced investigators to ascertain the truth by means of well-aimed questioning.

The advantage of this method is the promptness of the checking the individual person. The device allows people to pass through the security unit within two to four minutes. Another merit of the system is that the person has no notion of the fact he or she is being scanned and therefore he or she will not try to circumvent the device as he or she could do for example in case of the polygraph alias lie detector (Hazelton, 2008).

\section{CONCLUSION}

The mindreader system presents a great contribution to the detection of dangerous people in the future. The development of these systems is being constantly improved. It is only a matter of time before these systems will be deployed to crowded areas, and thus contribute significantly to the detection of a potential offender or terrorist and at the same time will contribute to the protection of a great number of people. Putting on these systems into airports can make taking liquids on the board accessible and speed up the passage security check too.

\section{ACKNOWLEDGEMENTS}

This article has been supported by a grant of IGA University of Thomas Bata in Zlin, Faculty of Applied Informatics, number IGA/38/FAI/11/D, IGA//FAI//D and by the European Regional Development Fund under the project CEBIA-Tech No. CZ.1.05/2.1.00/03.0089.

\section{REFERENCES}

Barrie, Allison. Foxnews.com [online]. September 23, 2008 [cit. 2011-05-25]. Homeland Security Detects Terrorist Threats by Reading Your Mind. Accessible from: http://www.foxnews.com/story/0,2933,426485,00.html

Hazelton, Liz. Science\&Tech [online]. 24th September 2008 [cit. 2011-05-27]. The airport security scanner that can read your mind. Accessible from: http://www.dailymail.co.uk/sciencetech/article1060972/The-airport-security-scanner-read-mind.html

Korenar, Patrik. Doctor-TV [online]. 21th July 2011 [cit. 201108-30]. The new scanner can read a simple idea. Accessible from: <http://www.doctor-tv.cz/article/98-novy-skenerdokaze-cist-jednoduche-myslenky>

Marks, Paul. New Scientist [online]. 10 August 2007 [cit. 201105-28]. Can a government remotely detect a terrorist's thoughts? Accessible from: $<$ http://www.newscientist.com/article/dn12458-can-agovernment-remotely-detect-a-terroriststhoughts.html?full=true>

Singer, Emily. Stop harassment and psychological Stalking [online]. 10/21/2009 [cit. 2011-08-25]. Technology for reading ideas. Accessible from: http://psychickeobtezovani.webnode.cz/news/technologiepro-cteni-myslenek/ 